hospital size were independently associated with EVS utilization. EVS increased significantly and continuously from 2010 to 2017 ( $\mathrm{p}$ for trend <0.001) whereas shunting and ONF use remained stable (Abstract 24 figure 1). Length of hospital stay was considerably lower following EVS (median 1, IQR 1-2) as compared to ONF (median 4, IQR 2-7) and shunting procedures (median 2, IQR 1-4) $(\mathrm{p}<0.01)$.

Conclusion This study presents novel population-level data on national trends in the frequency and characteristics of venous stenting in IIH. EVS was associated with shortest length of hospital stay. A continuous increase in venous stenting with a relative stable use of shunting and ONF suggests an increasing role for endovascular therapies in IIH.

Disclosures H. Saber: None. R. Jahan: 2; C; Medtronic, Balt. S. Tateshima: 2; C; Medtronic, Stryker, Cerenovus. G. Colby: 2; C; Stryker, MicroVention, Medtronic. N. Kaneko: None. M. Nour: None. V. Szeder: None. K. Khatibi: None. L. Ponce Mejia: None. D. Liebeskind: 2; C; Stryker. G. Duckwiler: 2; C; Medtronic.

\section{P-025 LARGE SCALE, CT EVALUATION CAN IMPROVE ACCESS TO IMAGING STUDIES WITHIN MULTI-CENTER STROKE TRIALS}

'B Jankowitz*, ${ }^{2}$ D Davies, ${ }^{3} \mathrm{~J}$ Day, ${ }^{4} \mathrm{~S}$ Chowdhry, ${ }^{5} \mathrm{C}$ Schirmer, ${ }^{6} \mathrm{~N}$ Levkovitz, ${ }^{7} \mathrm{O}$ Bibas, ${ }^{7}$ E Blanc, ${ }^{8} \mathrm{G}$ Pradilla. ${ }^{1}$ Neurosurgery, Cooper Neurological Institute, Camden, NJ; ${ }^{2}$ Neurosurgery, UBNS, Buffalo, NY; ${ }^{3}$ Neurosurgery, UAMS, LIttle Rock, AR; ${ }^{4}$ Neurosurgery, NorthShore, glenview, IL; ${ }^{5}$ Neurosurgery, Geisinger, Wilkes Barre, PA; ${ }^{6}$ Viz.ai, Viz.ai, Israel, Israel; ${ }^{7}$ Viz.ai, Israel, Israel; ${ }^{8}$ Neurosurgery, Emory, Atlanta, GA

\subsection{6/neurintsurg-2021-SNIS.61}

Introduction Artificial intelligence (AI) can automate the detection and triage of Intracerebral Hemorrhage (ICH). Early Minimally invasive Removal of IntraCerebral Hemorrhage (ENRICH) is a RCT evaluating the efficacy of minimally invasive surgery (MIS) for ICH. AI ENRICH is a prospective trial operating within and in parallel to the ENRICH trial that utilizes an AI application, Viz RECRUIT ICH Volume, to identify and segment ICH to quickly identify potentially eligible subjects.

Methods Non-contrast CT scans performed at 5 participating US hospitals were evaluated specifically for a parenchymal hemorrhage by Viz RECRUIT ICH Volume. Participating health care professionals downloaded a phone application that allowed users to be notified for any hemorrhage $\geq 5 \mathrm{~mL}$. Time metrics included the onset of CT scan, phone alert, and user recognition of that alert.

Results Over a combined period of 374 days, 24,137 CT scans were evaluated by the Viz ICH VOLUME application. Of these, 817 CT scans were determined to contain an $\mathrm{ICH}$ yielding a total of 154 patients that met ENRICH criteria for trial inclusion $(30-80 \mathrm{~mL})$. The median time from CT scan to cell phone notification was 2.6 minutes. The median time from cell phone notification to the user viewing the CT scan was 2.95 minutes.

Conclusions Viz ICH VOLUME can screen large numbers of CT scans and send alerts within minutes to medical professionals searching for clinical trial candidates in time-sensitive environments. Studies relying on radiographic selection criteria may benefit from automated screening.

Disclosures B. Jankowitz: 2; C; Stryker, Medtronic. J. Davies: None. J. Day: None. S. Chowdhry: None. C. Schirmer: None. N. Levkovitz: 5; C; Viz.ai. O. Bibas: 5; C; Viz.ai. E. Blanc: 5; C; Viz.ai. G. Pradilla: None.

\section{P-026 AQUA EMBOLIC SYSTEM: EVALUATING THE PERFORMANCE OF A NEW LIQUID EMBOLIC SYSTEM USING A SWINE AVM MODEL}

1I Yuki ${ }^{*},{ }^{2} \mathrm{~K}$ Ohkawa, ${ }^{3} \mathrm{~S} \mathrm{Li},{ }^{3} \mathrm{E}$ Steward, ${ }^{1} \mathrm{~B}$ Nguyen, ${ }^{1} \mathrm{~F} \mathrm{Hsu},{ }^{1} \mathrm{~J} \mathrm{Xu}_{1},{ }^{1} \mathrm{~S}$ Suzuki. ${ }^{1}$ Neurosurgerey, UC Irvine Medical Center, Orange, CA; ${ }^{2}$ Fiber Engineering, Institute for Fiber Engineering, Shinshu University, Ueda, Nagano, Japan; ${ }^{3}$ Surgery, UC Invine Medical Center, Orange, $C A$

10.1136/neurintsurg-2021-SNIS.62

Introduction Currently available Liquid Embolic Materials (LEMs) have limitations of potential catheter entrapment or

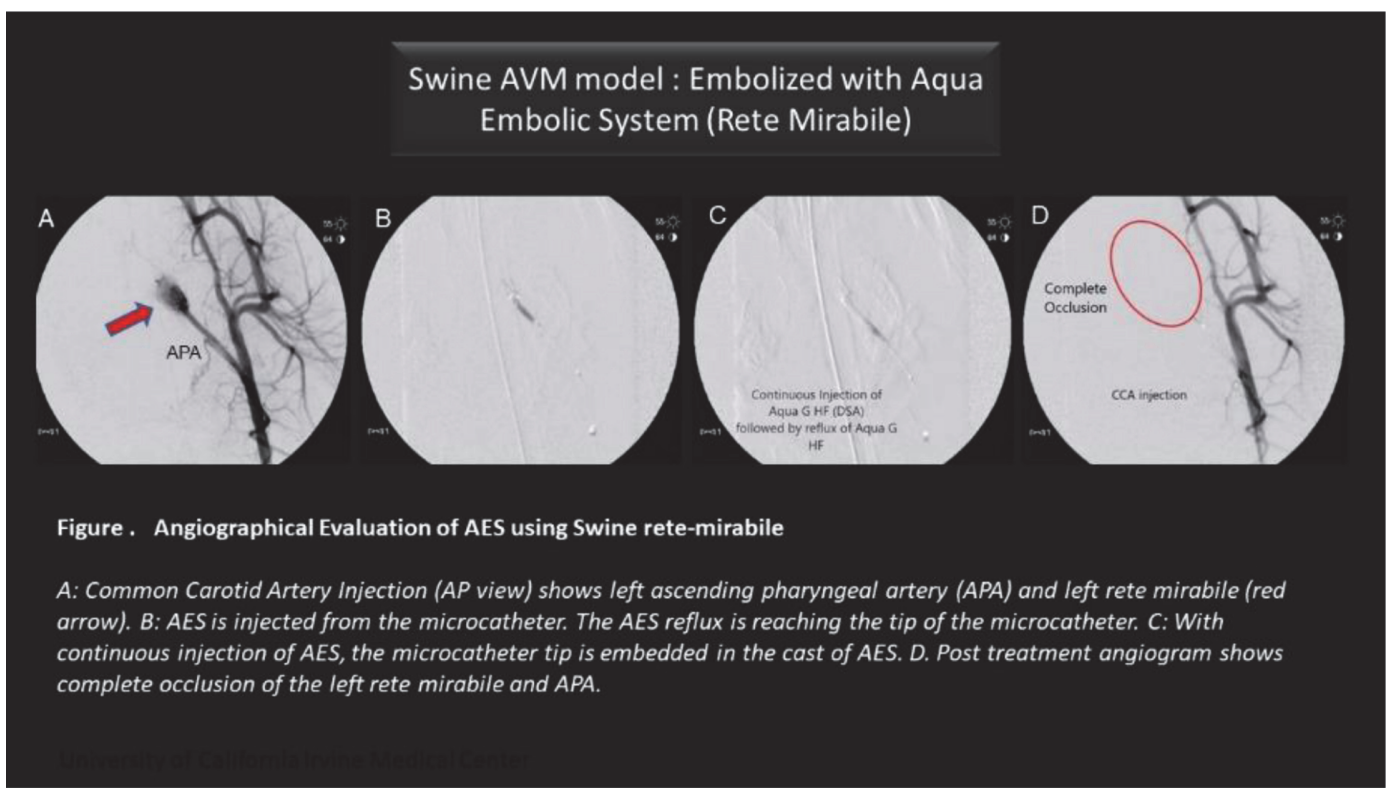

Abstract P-026 Figure 1 Angiographical evaluation of AES using swine rete-mirabile 
cytotoxicity of organic solvents (e.g., Dimethyl Sulfoxide (DMSO)). Aqua Embolic System (AES) is a new LEM, which is mainly composed of multiple polysaccharides. AES, when injected via a microcatheter, immediately forms a solid and elastic hydrogel cast upon exposure to $\mathrm{Ca} 2+$ in the bloodstream. The use of organic solvents, e.g., DMSO, is not required. The performance of AES was evaluated using an established AVM model utilizing swine rete-mirabile.

Methods Under general anesthesia, the left ascending pharyngeal artery (APA) of Yorkshire swine $(40 \mathrm{~kg})$ was catheterized using a microcatheter (ID:0.013 inches), and AES was slowly injected into the rete-mirabile under fluoroscopy. The following parameters were assessed to evaluate the embolization performance of the AES; 1) the amount of AES required for the complete occlusion of the feeding artery, 2) injection speed, 3) radiopacity during the deployment, and 4) incidence of catheter entrapment after the injection. The same evaluation was performed on the contralateral rete-mirabile and the left renal artery as well.

Results 12 arteries in 4 swine were treated, and all arteries were completely occluded without technical complications. The injected materials immediately formed AES cast in all vessels, followed by the reflux over the tip of the microcatheter. All catheters were withdrawn without any sign of catheter entrapment. The AES mixed with tantalum-based contrasts medium showed sufficient radiopacity under fluoroscopy. With the injection speed of $0.02 \mathrm{ml} / \mathrm{sec}$, the average volume required was $0.85 \mathrm{~mL}$ for the APA and $2.9 \mathrm{~mL}$ for the renal artery. No increased thrombogenicity or vasospasm near the treated lesion was observed during the procedure.

Conclusions AES, which is a DMSO free, non-adhesive polysaccharides based LEM, may be used as an embolic material for the treatment of hemorrhagic stroke caused by cerebrovascular diseases, such as brain AVM.

A: common carotid artery injection (AP view) shows left ascending pharyngeal artery (APA) and left rete mirabile (red arrow). B: AES is injected from the microcatheter. The AES reflux is reaching the tip of the microcatheter. C: With continuous injection of AES, the microcotheter tip is embedded in the cost of AES. D. Post treatment angiogram shows complete occlusion of the left rete mirabile and APA

Disclosures I. Yuki: 1; C; ICTS Grant, POP Grant. K. Ohkawa: None. S. Li: None. E. Steward: None. B. Nguyen: None. F. Hsu: None. J. Xu: None. S. Suzuki: None.

\section{P-027 ULTRA-EARLY FUNCTIONAL IMPROVEMENT AFTER STROKE THROMBECTOMY - PREDICTORS AND IMPLICATIONS}

${ }^{1} \mathrm{~S}$ Desai", ${ }^{1} \mathrm{D}$ Tonetti, ${ }^{1} \mathrm{G}$ Nayar, ${ }^{1} \mathrm{~A}$ Morrison, ${ }^{1} \mathrm{~K}$ Shah, ${ }^{2} \mathrm{~T}$ Jovin, ${ }^{1} \mathrm{~A}$ Jadhav. ${ }^{1}$ University of Pittsburgh Medical Center, Pittsburgh, PA; ${ }^{2}$ Cooper University, Camden, NJ

\subsection{6/neurintsurg-2021-SNIS.63}

Introduction Neurocritical care is routinely offered to patients post neurothrombectomy of anterior large vessel occlusion (LVO) strokes. We aim to study the relationship between immediate improvement in NIHSS score on outcomes post thrombectomy and potential implications for requiring neurocritical care.

Methods We performed a retrospective review of anterior LVO (internal carotid/proximal middle cerebral artery) patients undergoing neurothrombectomy between January 2015-
December 2018. Demographic, clinical (NIHSS score on admission and within 30 minutes post recanalization, time last know well-TLKW), and imaging (ASPECTS, TICI, intracranial hemorrhage) information was analyzed. Ultra-early functional improvement (Ultra-EFI) was defined as NIHSS score $<6$ within 30 minutes of successful recanalization. We analyzed the incidence and predictors of ultra-EFI and explored reasons for neurological decline post ultra-EFI.

Results Of the 343 anterior LVO patients undergoing neurothrombectomy, mean age was $71 \pm 15$ and $46 \%$ were males. Mean NIHSS was $17 \pm 6$ and TLKW to arrival was $9 \pm 11$ hours. Ultra-EFI was observed in 23\% (79/343) of patients. Independent predictors of ultra-EFI include lower pre-treatment NIHSS (), favorable ASPECTS (), and lower systolic blood pressure (). Rates of 90-day-mRS 0 -2 were higher $(71 \%$ VS $33 \%, \mathrm{P}<0.01)$ and the rate of mortality $(8 \%$ VS $28 \%$, $\mathrm{P}<0.01$ ) was lower in the ultra-EFI group compared to the non-ultra-EFI group. Amongst patients with ultra-EFI, 1.3\% $(1 / 79)$ experienced increase in NIHSS by $\geq 4$ points. This patient received thrombolysis, achieved TICI-2B recanalization, and follow-up neuroimaging revealed a parenchymal hemorrhage and an infarct volume of $44 \mathrm{ml}$. None of the patients required continuous antihypertensive infusions.

Conclusion Approximately 23\% of anterior LVO stroke patients undergoing neurothrombectomy have a NIHSS score of $<6$ within 30 minutes of successful recanalization. Approximately $1 \%$ of them experience significant decline in neurological status within 24 hours of the procedure with the majority achieving functional independence at 90 days. Need for advance neurocritical care should be re-evaluated in these patients.

Disclosures S. Desai: None. D. Tonetti: None. G. Nayar: None. A. Morrison: None. K. Shah: None. T. Jovin: None. A. Jadhav: None.

\section{P-028 OPHTHALMIC ARTERY FLOW DIRECTION CHANGES IN INTRA-ARTERIAL TREATMENT OF RETINOBLASTOMA}

${ }^{1} \mathrm{M}$ Feldman*, ${ }^{1} \mathrm{H}$ Grimaudo, ${ }^{1} \mathrm{~S}$ Roth, ${ }^{2} \mathrm{H}$ Vance, ${ }^{3} \mathrm{~A}$ Daniels, ${ }^{1} \mathrm{M}$ Froehler. ${ }^{1}$ Neurosurgery, Vanderbilt University Medical Center, Nashville, TN; ${ }^{2}$ Pediatric Neurosurgery, Vanderbilt University Medical Center, Nashville, TN; ${ }^{3}$ Department of Ophthalmology and Visual Sciences, Vanderbilt University Medical Center, Nashville, TN

\subsection{6/neurintsurg-2021-SNIS.64}

Introduction/Purpose The introduction of catheter-administered intra-arterial chemotherapy (IAC) has changed the treatment paradigm for retinoblastoma (RB), the most common ophthalmologic malignancy in children. The variable nature of ophthalmic artery flow has led to the development of multiple endovascular techniques for drug delivery. These methods are based on the direction of ophthalmic artery filling, either retrograde from anastomoses with branches of the external carotid artery (ECA) or anterograde from the internal carotid artery (ICA). These include direct catheterization of the ophthalmic artery, ECA branch selection, use of an ICA balloon occlusion with proximal IAC administration, and balloon occlusion of the ECA to halt anastamotic flow to the OA.We sought to evaluate both direction of ophthalmic artery flow at the onset of IAC, as well as identify reversal of ophthalmic artery flow during the course of treatment.

Materials and Methods We performed a retrospective analysis of the most recent 15 consecutive patients with $\mathrm{RB}$ who completed treatment with IAC at our tertiary care center. 